\title{
Larvicidal Effect of Vorticella microstoma (Ehrenberg, 1830) on Mosquito Larvae, and Morphological Changes under Induced Environmental Conditions
}

\author{
Achini Koshila Ranasinghe and L. D. Amarasinghe \\ Department of Zoology and Environmental Management, Faculty of Science, University of Kelaniya, Dalugama, \\ Kelaniya 11600, Sri Lanka \\ Correspondence should be addressed to L. D. Amarasinghe; deepika@kln.ac.lk
}

Received 26 March 2020; Revised 5 August 2020; Accepted 21 August 2020; Published 1 September 2020

Academic Editor: Bernard Marchand

Copyright (c) 2020 Achini Koshila Ranasinghe and L. D. Amarasinghe. This is an open access article distributed under the Creative Commons Attribution License, which permits unrestricted use, distribution, and reproduction in any medium, provided the original work is properly cited.

\begin{abstract}
Development of microbiota assemblage usually occurs in all most all domestic and peridomestic mosquito breeding habitats. There may be parasitic, epibiont, pathogenic, or even predatory species among this biota, and to investigate their potential against the mosquito population is worth studying. This may contribute to formulating environmentally agreeable approaches in controlling mosquitoes which is a current need. Vorticella spp. is a peritrich ciliate, and its trophont stage has become epibiont to certain biota. Further, their existence in seasonal water bodies that dry off during drought in tropical weather conditions is not known. Therefore, the potential of the larvicidal effect of Vorticella microstoma on different species of mosquito larvae was studied. We found that $V$. microstoma causes the $100 \%$ death of the third instar larvae of Culex tritaeniorhynchus (Giles, 1901) within $48 \mathrm{~h}$ of exposure. In contrast to that, this species did not cause any mortality to Aedes albopictus (Skuse, 1894) and Aedes aegypti (Linnaeus in Hasselquist, 1762) mosquito larvae in repeated trials. The dynamics of polymorphism of $V$. microstoma was studied under induced environmental conditions. $V$. microstoma remained as trophont stage throughout at room temperature $\left(25 \pm 2^{\circ} \mathrm{C}\right)$. When the temperature was reduced to $6^{\circ} \mathrm{C}, \mathrm{V}$. microstoma settled in the cyst stage. Evidently, V. microstoma is a good biocontrol agent of Culex species mosquito larvae, and they able to overcome drought periods in cyst forms. The findings of this study would be considered as the first step for a new avenue to work on environmentally agreeable manner in reducing the Culex spp. mosquito populations.
\end{abstract}

\section{Introduction}

Mosquitoes transmit most of the life-threatening diseases like malaria, filariasis, Japanese encephalitis, dengue fever, chikungunya fever, yellow fever, West Nile virus infection, and ZIKA fever [1]. Therefore, mosquito control is essential to prevent the proliferation of mosquito-borne diseases and to improve the quality of the environment and public health. The best approach is either killing adult mosquitoes preventing them from biting people or by killing the larvae at breeding sites, to interrupt the disease transmission [2].

The common mosquito larvicides are organophosphates and pyrethroids. However, the effectiveness of the vector control by the synthetic insecticides has declined due to the development of resistance in mosquitoes to currently used insecticides [2]. In addition to that, the health risks for human and domestic animals and disturbances to the natural balance such as predator-prey or parasite-host relationships warrant formulating environmentally agreeable approaches in controlling mosquitoes.

There is always a varying level of microbiota assemblage among the biotic factors in all most all these mosquito breeding habitats. Among these living beings, there may be freeliving, parasitic/epibiont, pathogenic, or even predatory species that can affect the life of the developing mosquito immatures. Some of the biota serve as food items of the larvae, 
while some may serve as parasitic/epibiont in living in the body of the mosquito larvae, and some may serve as predators [3].

Vorticella Ehrenberg is a suspension-feeding ciliate that lives in two forms: the free-swimming telotroch and the sessile stalked trophont [4]. The stalked Vorticella has contractile myonemes, allowing them to pull the cell body against substrates [5]. A sessile V. microstoma consists of a single zooid, body vase-like, with a long contractile stalk [6].

Further, Vorticella sp. is a microbiota species associated with mosquito breeding habitats in cultivated and abandoned rice fields of Sri Lanka [3], and it has been found to occasionally infect mosquito larvae in other countries [710]. Vorticella sp. has been explored as a biocontrol agent of mosquitoes recently [11].

Warren [12] has reported the formation of a cyst around the body of Vorticella during unfavorable conditions. Further, Warren [12] reports that the encysted body breaks off from the stalk. In this condition, Vorticella tides over the unfavorable conditions. After the return of favorable conditions, the cyst breaks and the individual emerges, develops a contractile vacuole, and becomes enlarged. It grows an aboral circlet of cilia to become a telotroch. It swims freely for some time and then settles on some substratum, develops a stalk, and grows into an adult Vorticella.

Therefore, the present study was conducted to (1) maintain and cultivate $V$. microstoma collected from natural mosquito breeding habitats under laboratory conditions; (2) determine the larvicidal effect of $V$. microstoma to selected mosquito species and instar levels; (3) determine the different morphological forms of $V$. microstoma under induced environmental conditions.

\section{Materials and Methods}

2.1. Field Collection of Vorticella microstoma and Maintenance in the Laboratory. V. microstoma used in this study were originally recovered together with moribund and dead Culex tritaeniorhynchus larvae in $200 \mathrm{~mL}$ water samples collected from a cultivated paddy field in Melsiripura in Kurunegala district, Sri Lanka (GPS location: $\left.7^{\circ} 37.579^{\prime} \mathrm{N}, 80^{\circ} 29.618^{\prime} \mathrm{E}\right)$. This site was identified as $V$. microstoma positive selected abiotic variables, namely; $\mathrm{pH}$ and dissolved oxygen (DO) of water of the sampling site were measured using a multiparameter (HACH-HQ40d) in a manner that $1 / 4$ of the probe is dipped in water, in situ. Determination of the five-day biological oxygen demand (BOD5) was carried out as described in APHA [13]. pH, DO, and BOD of the sampling site were measured as $7.15,6.99 \mathrm{mg} \mathrm{L}^{-}$ 1 and $6.87 \mathrm{mg} \mathrm{L}^{-1}$, respectively.

Water samples from the paddy field $(n=15)$ were brought into the laboratory in plastic containers, with $C x$. tritaeniorhynchus mosquito larvae. After two days, the dead $C x$. tritaeniorhynchus larvae were collected and observed under a microscope (OLYMPUS x C21; Jeff Liu Ningbo Huasheng Precision Technology International Trading Co., Zhejiang, China). The dead larvae having $V$. microstoma attached to their bodies were transferred at the rate of five larvae into wide-mouthed plastic bottles (height: $12 \mathrm{~cm}$, width: $6.5 \mathrm{~cm}$ ) filled with $50 \mathrm{~mL}$ distilled water. Ten well-cleaned and dried, $2.5 \mathrm{~cm}$-long pieces of hay were placed in each bottle as a substratum for the attachment of $V$. microstoma, while they are multiplying. The mouth of the bottles were individually covered with a small-sized mesh net and maintained for four days at room temperature $\left(25 \pm 2{ }^{\circ} \mathrm{C}\right)$ under laboratory conditions. The mean number of $V$. microstoma trophonts attached to a single piece of hay in a culture bottle was 60 \pm 5 at the initial stage. However, the mean number of trophonts contained in one culture bottle after 4 days period was estimated as $2500 \pm 300$. A series of $V$. microstoma culture bottles were prepared every five days to prevent the growth of other microbiota species, such as Philodina citrina (Rotifera) (Ehrenberg, 1832) and Paramecium (Müller, 1773). One such $V$. microstoma culture bottle was considered as an experimental unit and used for experimentations, as described in this study.

2.2. Collection of Mosquito Larvae and Species Identification. Aedes albopictus, Aedes aegypti, Cx. tritaeniorhynchus, Culex gelidus (Theobald, 1901), and Tripteroides spp. (Giles, 1904) larvae were collected from Kelaniya $\left(06^{\circ} 58.426^{\prime} \mathrm{N}\right.$, $\left.79^{\circ} 54.939^{\prime} \mathrm{E}\right)$, Ragama $\left(07^{\circ} 02.660^{\prime} \mathrm{N}, 79^{\circ} 55.957^{\prime} \mathrm{E}\right)$, Kurunegala $\left(7^{\circ} 35.510^{\prime} \mathrm{N}, \quad 80^{\circ} 26.413^{\prime} \mathrm{E}\right)$, Nahena $\left(6^{\circ} 59.707^{\prime} \mathrm{N}\right.$, $\left.79^{\circ} 54.758^{\prime} \mathrm{E}\right)$, and Alawwa $\left(7^{\circ} 18.493^{\prime} \mathrm{N}, 80^{\circ} 15.712^{\prime} \mathrm{E}\right)$, respectively. Species identification was confirmed by standard identification guides of mosquito larvae [14-16].

2.3. Larvicidal Rate of V. microstoma on Mosquito Larvae. The larvicidal assay was performed according to the guidelines of WHO [17]. Fifteen third-instar mosquito larvae were introduced into $V$. microstoma culture bottles $(n=10)$ at room temperature. After $48 \mathrm{~h}$ of exposure, the number of dead mosquito larvae was counted. Dead larvae were picked using a pasture pipette and placed on a microscopic glass slide containing a drop of saline. Thereafter, they were observed under a microscope (OLYMPUS x C21; magnification $100 \mathrm{x}$ ). Larvae infected with $V$. microstoma were identified by the presence of epibionts attached to the body surface. Culex tritaeniorhynchus, Ae. albopictus, and Tripteroides spp. larvae, and a combination of equal numbers of two mosquito species, Cx. tritaeniorhynchus and Tripteroides spp., were tested. One set of control was maintained for each treatment.

Fifteen each of the first, second, and third instar larvae of Cx. gelidus and Ae. aegypti were placed in separate V. microstoma culture bottles at room temperature. Three replicates were run for each instar level. After 24 and $48 \mathrm{~h}$, the number of dead mosquito larvae was counted. The dead larvae were observed under a microscope (OLYMPUS x C21; magnification $40 \mathrm{x}$ ), and heavily infested larvae with $V$. microstoma were identified by the presence of epibionts attached all over the body surface. One set of controls were maintained for each treatment.

2.4. Effects of Variation in Temperature and Dehydration on the Different Morphological Forms of $V$. microstoma. $V$. microstoma trophont stage colony formed on $2.5 \mathrm{~cm}$-long hay pieces from 4 days old culture bottles were collected 


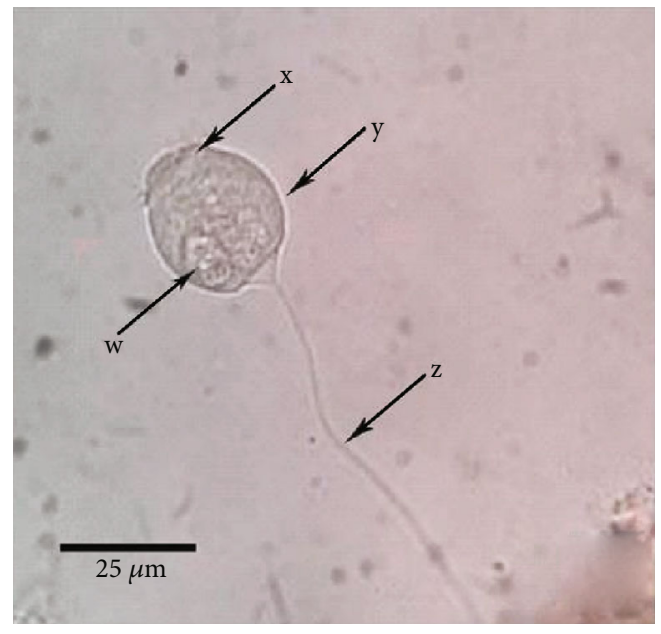

(a)

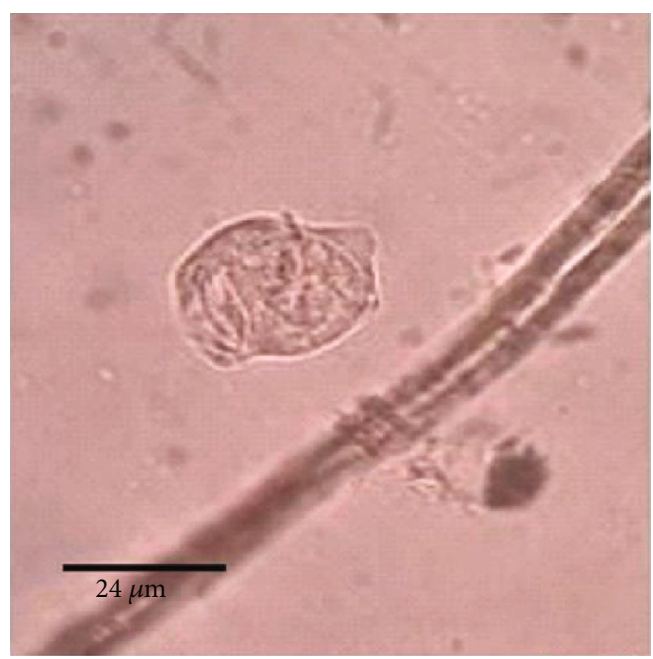

(c)

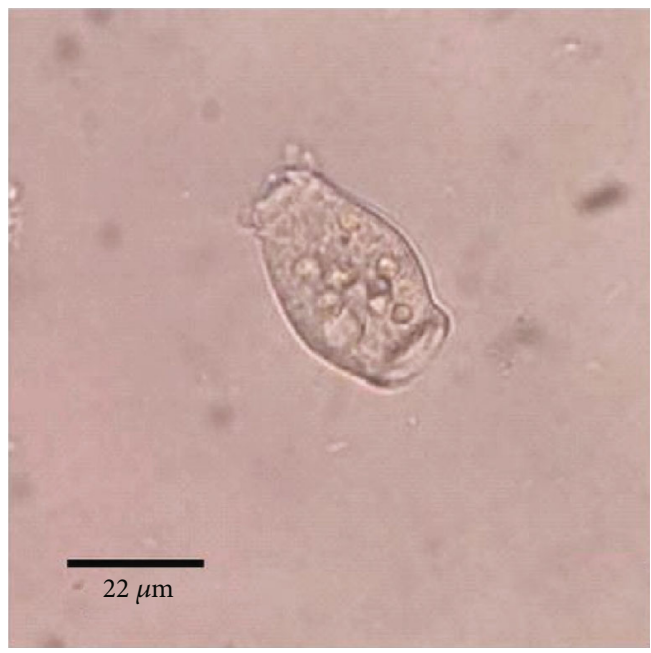

(e)

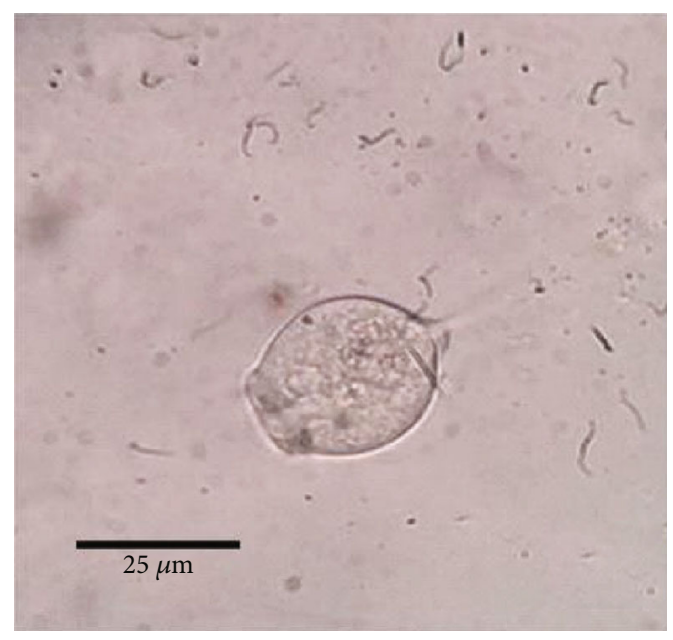

(b)

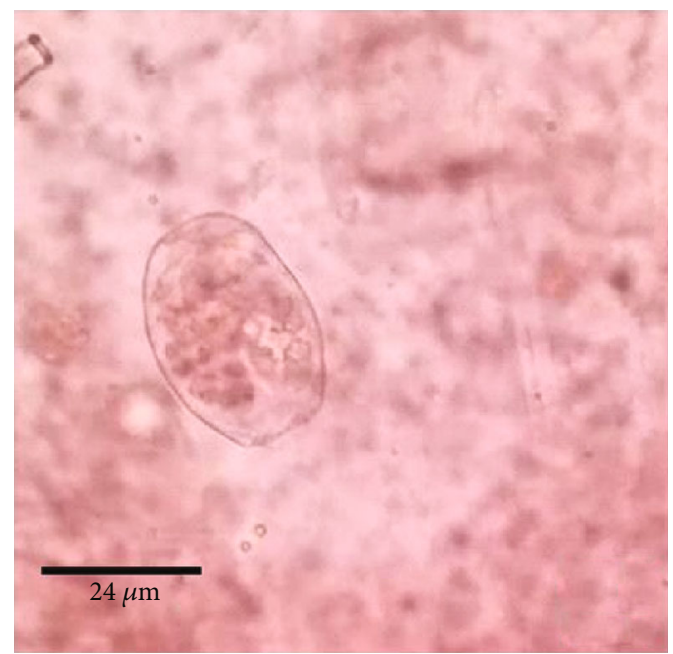

(d)

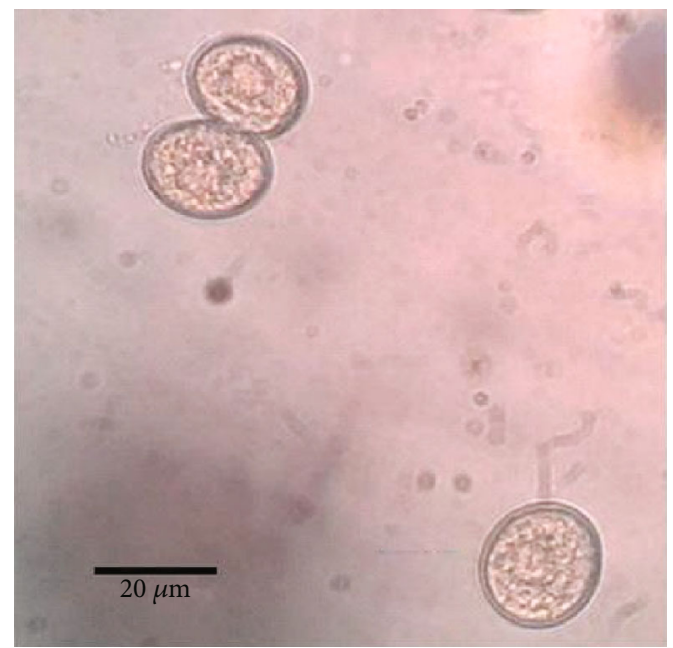

(f)

FIGURE 1: Different morphological forms of V. microstoma ((a) sessile stalked trophont stage (w: contractile vacuole, x: oral cilia, y: cup-like body, c: contractile stalk), (b) detached cup-like body with a short stalk, (c) detached cup-like body without a stalk, (d) intermediate stage between cup-shape and elongated shape, (e) elongated telotroch stage, (f) cyst stage) $(\times 400)$. 


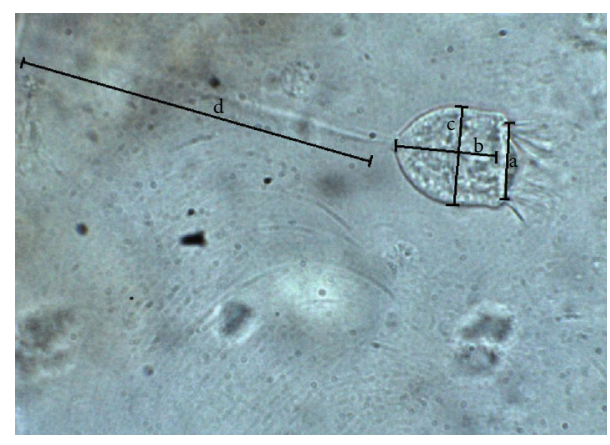

Figure 2: Microscopic view of the trophont stage of $V$. microstoma $\times 400$ ((a) width of the open peristome; (b) length of the body; (c) width of the body; (d) length of the contractile stalk).

and one piece was placed in each petri dish of diameter $9 \mathrm{~cm}$ and depth $0.8 \mathrm{~cm}(n=18)$. They were placed under six different conditions in three replicates.

(1) At room temperature $\left(25 \pm 2^{\circ} \mathrm{C}\right), 30 \mathrm{~mL}$ of distilled water was added into the dish

(2) At room temperature $\left(25 \pm 2^{\circ} \mathrm{C}\right)$, no water was added; dehydration was induced

(3) At $11^{\circ} \mathrm{C}$ in a bottle cooler, $30 \mathrm{~mL}$ of distilled water was added into the dish

(4) At $11^{\circ} \mathrm{C}$ in a bottle cooler, no water was added; dehydration was induced

(5) At $6^{\circ} \mathrm{C}$ in a refrigerator, $30 \mathrm{~mL}$ of distilled water was added into the dish

(6) At $6^{\circ} \mathrm{C}$ in a refrigerator, no water was added; dehydration was induced

Changes in the morphology of $V$. microstoma were observed under the microscope after $24 \mathrm{~h}$.

\subsection{Viability of the Cyst Stage of V. microstoma under} Prolonged Dry Condition. The cysts of $V$. microstoma formed on hay pieces under dehydrating conditions in the previous experiment were placed individually on a filter paper placed at the bottom of petri dishes with diameter $9 \mathrm{~cm}(n=10)$, thus allowing the cysts to continuously dry at room temperature $\left(25 \pm 2^{\circ} \mathrm{C}\right)$. In each $24 \mathrm{~h}$ interval, one petri dish was taken and $5 \mathrm{ml}$ of water was added, and this was continued for 21 days. Morphological changes to $V$. microstoma cyst after water addition were observed after $24 \mathrm{~h}$, and the data were recorded.

2.6. Data Analysis. Mosquito larval mortality data were analyzed using IBM SPSS Statistics 22 software (developed by International Business Machines Corporation-IBM, US). The mortality effect of $V$. microstoma on different mosquito species and between different larval instar levels were analyzed using one-way ANOVA and post hoc comparisons.

\section{Results}

3.1. Mosquito Larvicidal Effect of V. microstoma. The mosquito larvae were observed under a microscope (40x magnification) and identified as infested with an epibiont, which is the live sessile stalked trophont stage of $V$. microstoma, with a cup-shaped body and a contractile stalk attached to the substrate (Figure 1(a)). Speciation was performed using key morphological characteristics, the body is vase-like; slightly yellowish; anterior region (= "peristome") with buccal ciliation that winds counterclockwise to the buccal cavity; anterior region rather narrow (Figure 1(a)) by comparison with other species of the genus; one long band form macronucleus extending more or less along the longitudinal axis of the cell; a single micronucleus; a contractile vacuole is located in the buccal cavity; usually solitary, although sometimes in large groups. Mature sessile individuals without body ciliation were found [18]. Body length: $49.984 \mu \mathrm{m} \pm$ 3.41 , body width: $27.098 \mu \mathrm{m} \pm 1.42$, the width of open peristome: $19.74 \mu \mathrm{m} \pm 3.10$, and the length of the contractile stalk: $80.23 \mu \mathrm{m} \pm 14.94$ (Figure 2) were observed.

Higher densities of this organism were attached to the saddle and head regions (Figures 3 and 4), followed by the abdominal regions of the body of dead mosquito larvae. $V$. microstoma usually did not attach to the siphon region of live mosquito larvae; instead, they attached to other regions of the body. However, V. microstoma attached to the siphon and head regions once the larvae died.

Culex tritaeniorhynchus was the most preferred host of the trophont stage of $V$. microstoma, causing the death of $100 \%$ of the mosquito larvae, followed by Tripteroides spp., in which $46.7 \%$ of the larvae died. Aedes albopictus larvae were not preferred by $V$. microstoma. Therefore, the mortality rate of Ae. albopictus due to $V$. microstoma was zero (Figure 5). The mean mortality percentage of the mosquito species studied were significantly different from each other (one-way ANOVA: $0.001<P<0.05, F=24.143$ ). According to multiple comparisons, the mortality percentage of $C x$. tritaeniorhynchus was significantly higher than that of Tripteroides spp. and Ae. albopictus larvae (one-way ANOVA post hoc comparisons Sig. $0.010<0.05,0.000<0.05$, respectively) (Table 1).

Culex tritaeniorhynchus larvae showed more susceptibility than Tripteroides spp. larvae did for infection by V. microstoma when both these species were kept together; however, the mortality did not differ significantly from each other (one-way ANOVA: $P=0.374<0.05, F=1.000$ ) showing that there is a reducing tendency in the of mortality of $C x$. tritaeniorhynchus $(33.3 \pm 11.54)$ compared to that of Tripteroides spp. $(20 \pm 10)$.

3.2. Susceptibility of Cx. gelidus and Ae.aegypti Larval Instar Levels to $V$. microstoma. The first, second, and third instar larvae of $C x$. gelidus were infested with the trophont stage of $V$. microstoma. None of the instar levels of Ae. aegypti showed susceptibility to infection with $V$. microstoma. In the first instar larvae of Cx. gelidus, 30-35 V. microstoma got attached with higher densities found in the thoracic region followed by the other segments (Figure 6), whereas 


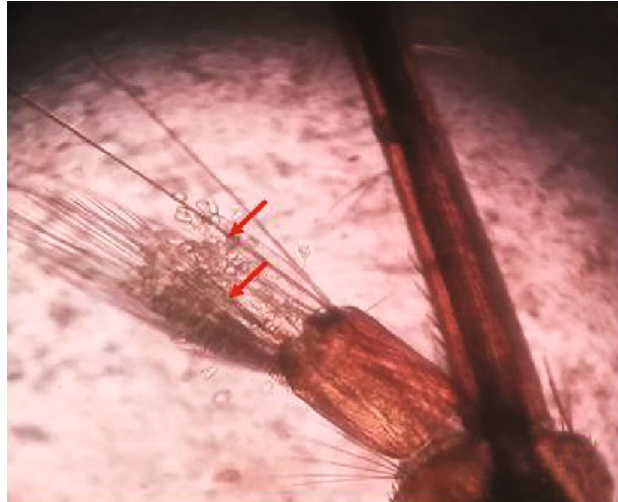

(a)

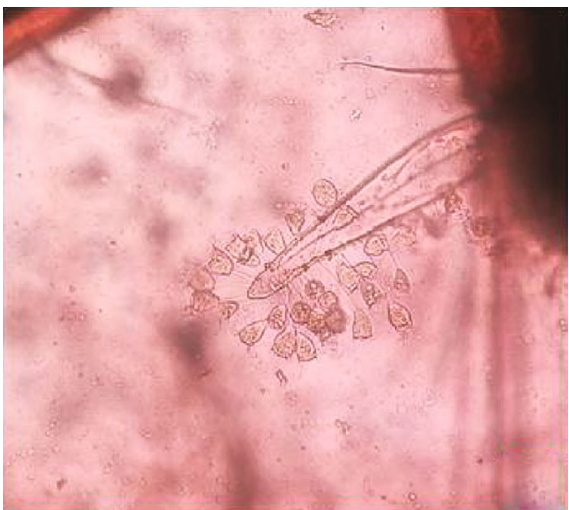

(b)

FIGURE 3: Infection of the parasite (V. microstoma) to $3^{\text {rd }}$ larval instars of $C x$. tritaeniorhynchus anal papillae region $(\times 40$ magnification), and attached trophonts of $V$. microstoma ( $\times 100$ magnification).

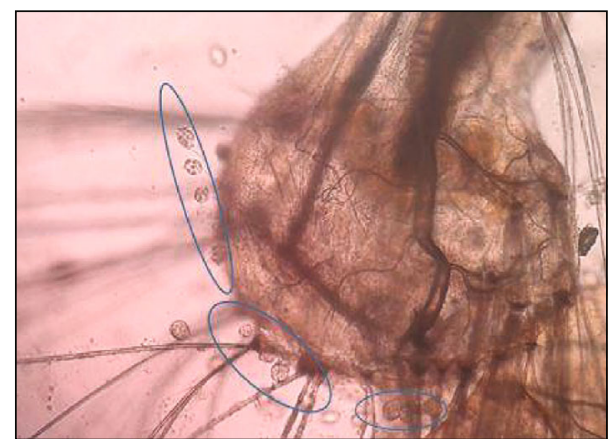

FIgURe 4: V. microstoma infected dead Cx. tritaeniorhynchus $3^{\text {rd }}$ instar larvae head region $(\times 400)$ (attached trophonts to the body are shown inside circles of blue color).

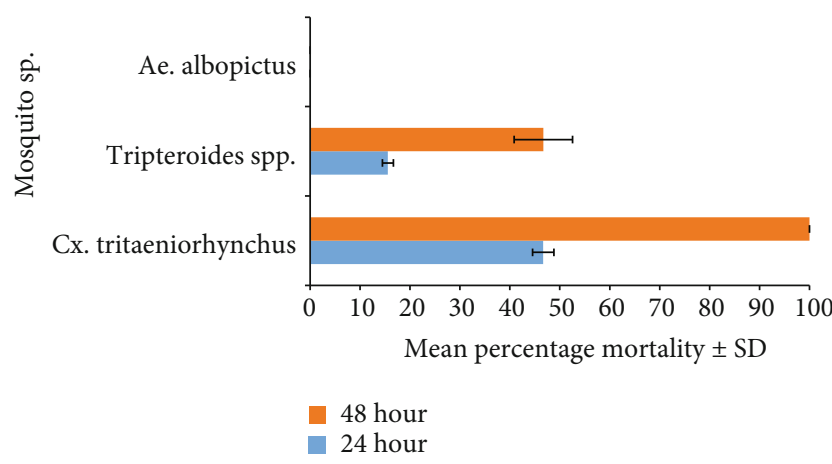

FIGURE 5: Mean percentage mortality of mosquito larvae $3^{\text {rd }}$ instars due to $V$. microstoma attachment. Control values remained zero mortality.

2-4 trophonts were attached to the anal papillae. In the second instar larvae of Cx. gelidus, 45-60 V. microstoma got attached, with higher densities in abdominal segments (Figure 7); in anal papillae, 5-6 trophonts were attached. In the third-instar larvae of Cx. gelidus 50-85 V. microstoma got attached, with higher densities in the anal papillae followed by abdominal segments (Figure 8); in the anal papil- lae, 20-25 trophonts were found to be attached. Mean mortality percentage of the different instars of $C x$. gelidus larvae are shown in Figure 9.

The percentage mortality of the first, second, and third instar larvae of $C x$. gelidus did not significantly differ from each other (one-way ANOVA: $P=0.298<0.05, F=1.494$ ). Multiple comparisons (one-way ANOVA post hoc comparisons) of mortality percentage of the first, second, and thirdinstar of Cx. gelidus larvae did not reveal significant differences as compared with that of all the other instar levels (Table 2). The mortality values of the controls remained zero.

3.3. Effects of Variation in Temperature and Dehydration on the Dynamics of $V$. microstoma Polymorphic Stages. At room temperature $\left(25 \pm 2^{\circ} \mathrm{C}\right)$ in aqueous condition, only the live sessile stalked trophont stage of $V$. microstoma was observed (Figure 1(a)). However, under dehydrated conditions with no water at room temperature $\left(25 \pm 2^{\circ} \mathrm{C}\right)$, only the cyst stage of $V$. microstoma was observed (Figure 1(f)) after $24 \mathrm{~h}$ of exposure. The cyst stage was round in its shape, without a contractile stalk, and had a clearly visible membrane around the cyst. In contrast, at $11^{\circ} \mathrm{C}$ under aqueous conditions, five different morphological stages of $V$. microstoma were observed: live sessile stalked trophont stage (Figure 1(a)), consisting of a detached cup-like body with a short, mobile stalk (Figure 1(b)); detached cup-like body without a mobile stalk (Figure 1(c)); an intermediate stage to telotroch stage (Figure 1(d)); telotroch stage, which is highly mobile (Figure 1(e)); the immobile cyst stage (Figure 1(f)). The detached cup-like bodies with a short, mobile stalk or without a stalk were freely-swimming stages. The telotroch stage was elongated and had a long cylinder-shaped body, without a contractile stalk. They had a posterior girdle of cilia and was a freely-swimming stage. Under these conditions, the telotroch stage was predominant. Exposure to $11^{\circ} \mathrm{C}$ and dehydration resulted in the presence of only the cyst stage of $V$. microstoma, which is immobile (Figure $1(\mathrm{f})$ ). The reduction of temperature to $6^{\circ} \mathrm{C}$, with or without water, caused only the immobile cyst stages of $V$. microstoma to be observed (Figure 1(f)). 
TABLE 1: Multiple comparison between mortality percentages of mosquito species (IBM SPSS Statistics 22 software).

\begin{tabular}{|c|c|c|c|c|c|c|}
\hline \multirow{2}{*}{ Replicate (I) } & \multirow{2}{*}{ Replicate (J) } & \multirow{2}{*}{ Mean difference (I-J) } & \multirow{2}{*}{ Std. error } & \multirow{2}{*}{ Significant level } & \multicolumn{2}{|c|}{ 95\% confidence interval } \\
\hline & & & & & Lower bound & Upper bound \\
\hline \multirow{2}{*}{ Cx. tritaeniorhynchus } & Tripteroides spp. & $53.33^{*}$ & 14.40 & 0.01 & 18.09 & 88.57 \\
\hline & Ae. albopictus & $100.00^{*}$ & 14.40 & 0.00 & 64.76 & 135.24 \\
\hline \multirow{2}{*}{ Tripteroides spp. } & Cu. tritaeniorhynchus & $-53.33^{*}$ & 14.40 & 0.01 & -88.57 & -18.10 \\
\hline & Ae. albopictus & $46.67^{*}$ & 14.40 & 0.02 & 11.43 & 81.91 \\
\hline \multirow{2}{*}{ Ae. albopictus } & Cx. tritaeniorhynchus & $-100.00^{*}$ & 14.40 & 0.00 & -135.24 & -64.76 \\
\hline & Tripteroides spp. & $-46.67^{*}$ & 14.40 & 0.02 & -81.91 & -11.43 \\
\hline
\end{tabular}

*The differences between mean values are significant at the 0.05 level.

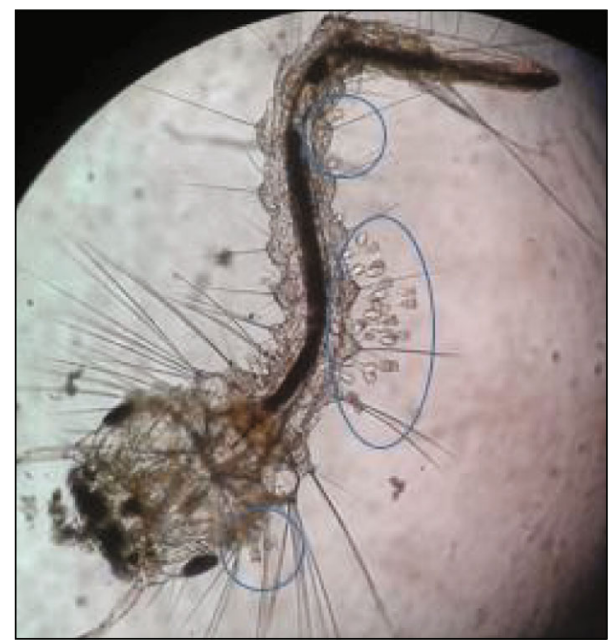

FIgURE 6: $V$. microstoma infected thoracic and abdominal region of $1^{\text {st }}$ instar larvae of $C x$. gelidus $\times 40$ ) (attached trophonts to the body are shown inside circles of blue color).

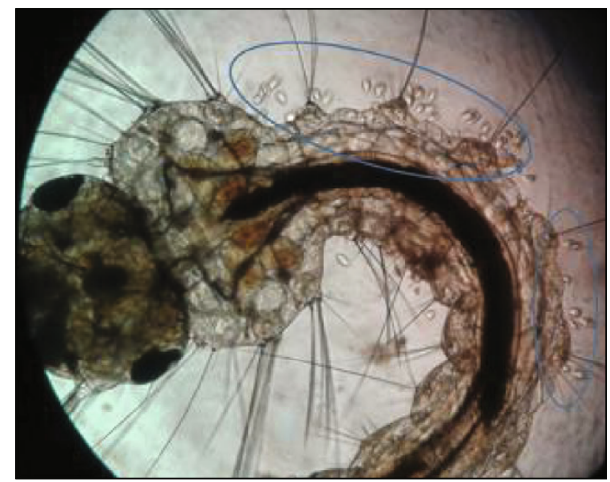

Figure 7: V. microstoma infected abdominal region of $2^{\text {nd }}$ instar larvae of $C x$. gelidus $(\times 40)$ (attached trophonts to the body are shown inside circles of blue color).

3.4. Viability of the Cyst Stage of V. microstoma under Prolonged Dry Conditions. After $24 \mathrm{~h}$ of exposure of V. microstoma in petri dishes to continuous dry conditions, only the immobile cyst stages were observed (Figure 1(f)). However, they were transformed to its trophont stage after addition of water and observing for $24 \mathrm{~h}$. The transformation of the cyst stage into the trophont stage was observed up to $21 \mathrm{~d}$. This indicates that under waterless dry conditions, the cyst stage of $V$. microstoma can survive up to 21 days under laboratory conditions.

\section{Discussion}

A study conducted by Patil et al. [11] revealed that the inhibition of larval growth, development, and adult emergence of An. stephensi larvae due to infection of Vorticella sp. Far back in 1950, Mick [9] reported the lethal effect of the ciliate, $V$. microstoma on An. quadrimaculatus, while the present study reveals the lethal effect of $V$. microstoma on $C x$. tritaeniorhynchus, Cx. gelidus, Cx. quinquefasciatus, and An. subpictus mosquito larvae. The reason for the death of mosquito larvae due to attachment of Vorticella is still not well understood. Mick [9] stated that the larval death may be apparent due to the inability of the infected larvae to remain on the water surface, thereby interfering with respiration and drowning. However, Patil et al. [11] presumed that the organism secretes some biochemical substances to fix itself on the substrate, and those substances may damage some surface sensory system or cause pore formation in the larval body. It is also possible that the metabolic and secretory products of Vorticella are toxic to the mosquito larvae, polluting its natural environment [11]; hence, the use of Vorticella has been explored as a biocontrol strategy for mosquitoes. The present study reveals the drowning of moribund mosquito larvae in water. It is also possible that the metabolic and secretory products of Vorticella species are toxic to mosquito larvae [11]. Besides mosquito larvae, Vorticella species have been found attached to the integument of nematodes, tardigrades, and chironomids as well and the nematodes within fresh extracts from soil samples. Vorticella attached to the cuticle of nematodes was found to be moving initially but gradually became sluggish and finally died 18-24 hours after isolation [19].

In this study, $V$. microstoma trophonts did not usually attach to the siphon region of live mosquito larvae, most probably due to the hardness of the cuticle. However, they attached to the siphon region once the infected mosquito larvae are dead possibly owing to the reduction of the thickness of the siphon cuticular layer due to autolysis. Ae. albopictus and $A e$. aegypti did not show any infestation or mortality due to $V$. microstoma in the present study. The reason 


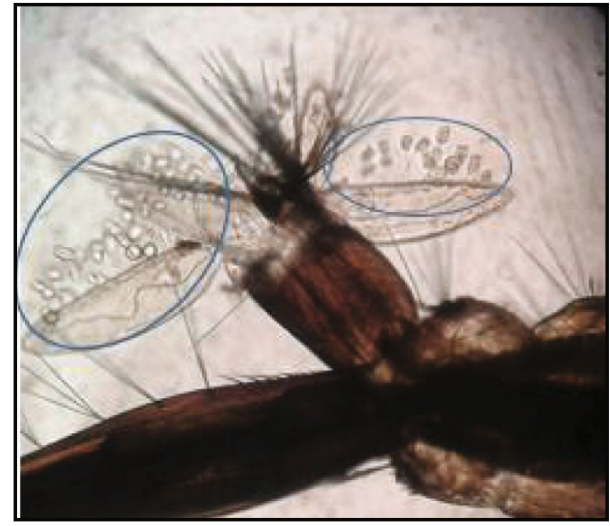

FIGURE 8: $V$. microstoma infected anal papillae of $3^{\text {rd }}$ instar larvae of Cx. gelidus $(\times 40)$ (attached trophonts to the body are shown inside circles of blue color).

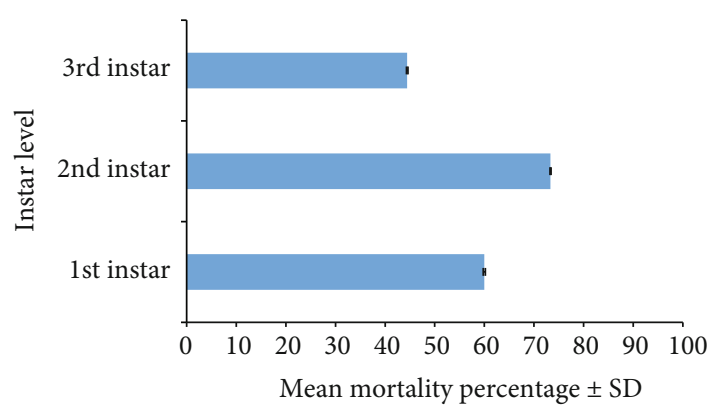

FIGURE 9: Mean mortality percentage \pm SD of different instar levels of $C x$. gelidus larvae.

underlying this is not clearly evident. Patil et al. [11] quoted from an unrecorded reference that Vorticella infection was found only in Anopheles spp., and infection or mortality was not observed in Ae. aegypti. However, their study showed that Vorticella sp. prefers Anopheles and suggested that attachment that it prefers other mosquito species such as Ae. aegypti as a second preference.

It has long been recognized that different species of Vorticella often have a predilection for different ecological conditions [12]. V. microstoma species sometimes stay in clusters or groups considered as pseudocolonies, but they are not true colonies because each cell has its own individual stalk. This allows it to detach from the cluster at any time, usually by reverting to a telotroch stage when environmental conditions are unfavorable $V$. microstoma also swim freely if they have to detach themselves from the substrate due to unfavorable condition. Thus, the sessile form can transform into a telotroch stage and becomes free-swimming in search of a congenial environment. The present study also reveals the encystation of $V$. microstoma under desiccation and excystation again when reflooding the cysts formed. The original ciliate sample was collected from a paddy field during the present study, As there are two major paddy transplantation seasons in Sri Lanka, coupled with two monsoon rain types; after the paddy is harvested, vector breeding habitats got limited with the restricted distribution of parasitic or pathogenic ciliates in host mosquito larvae. Thus, survival of the parasitic agent should undergo under dry conditions until the next season of paddy transplantation coupled with monsoon rains under high vector density situation returns. The encystation of $V$. microstoma seems a possible way for the time-lap of the dry season until the next paddy plantation period occurs with rain. After excystation, as V. microstoma has a high reproductive potential, the number of trophonts could be increased easily when the optimum environmental conditions reoccurred. Cysts and the processes of encystation and excystation have been described for V. microstoma [20].

Likewise, prolonged exposure to induced unfavorable conditions, such as temperature reduction, forced V. microstoma to transform through the telotroch stage to the cyst stage in this study. The cyst stage in the aqueous situation could transform to the trophont stage through the telotroch stage, and the cysts in prolonged dry conditions "without water" were able to survive up to 21 days.

When the food is exhausted, they got excysted, and the addition of bacteria cause also to excyst or to increase the size, and found with a higher multiplication rate under the presence of bacteria [21]. When starved, the ciliate is thinner, thus gets more elongated. When a trophont is well-fed with bacteria, trophont becomes swollen and striations in the body get no longer visible. The encysted $V$. microstoma gets commences with the formation of the contractile vacuole which pulsates, and the ciliate excysted from the cyst membrane through a cyst-pore, forced open by hydrostatic pressure due to the activity of the contractile vacuole. It took nearly an hour from signs of a contractile vacuole to the escape of the ciliate from the cyst membrane. Then, the escaped individual turns in to a telotroch, and then to sessile trophont [21].

Epibiont ciliates make up a significant part of the biomass in aquatic ecosystems and may cause perceptible alterations in the population dynamics of their hosts. A study carried out by Cabral et al. [21] found that the Chironomus genus, of which $16.95 \%$ were colonized by Rhabdostyla aff. chironomi, colonizing the chironomids' ventral tubules. The high number of chironomid larvae, high host- and site-specificity, low infestation intensity, and absence of apparent structural damage to hosts evidence an intimate relationship between epibiont and basibiont. But compared to that, epibiont interaction of $V$. microstoma with mosquito larvae, a host specificity was found, and the rate of infection with the epibiont was dependent on that [22]. The ciliate, Chilodonella uncinata was found to cause $25-100 \%$ of mortalities in larval stages of the JE vectors in North India and widely distributed in typical JE vector-breeding habitats [23]. Further, anopheline larvae found less susceptible to Chilodonella infection than culicine larvae revealing that this ciliate also has a different degree for pathogenism and host selection and host specificity over different species of mosquito larvae [23]. Therefore, host specificity seems to be an important factor for the degree of ciliate infections.

In the field of applied ecology, there have been many attempts to achieve the biological control of pathogens or vectors by introducing new effective natural enemies to their natural habitats [24]. The efficient selection of effective 
TABLE 2: Multiple comparison between mortality percentage of different instars of Cx. gelidus larvae (IBM SPSS Statistics 22 software).

\begin{tabular}{llccccc}
\hline \multirow{2}{*}{ Replicate (I) } & Replicate (J) & Mean difference (I-J) & Std. error & Significant level & \multicolumn{2}{c}{ 95\% confidence interval } \\
Lower bound & Upper bound \\
\hline \multirow{2}{*}{$1^{\text {st }}$ instar } & $2^{\text {nd }}$ instar & -13.33 & 16.73 & 0.46 & -54.27 & 27.61 \\
& $3^{\text {rd }}$ instar & 15.56 & 16.73 & 0.39 & -25.38 & 56.50 \\
\multirow{2}{*}{$2^{\text {nd }}$ instar } & $1^{\text {st }}$ instar & 13.33 & 16.73 & 0.46 & -27.61 & -12.05 \\
\multirow{2}{*}{$3^{\text {rd }}$ instar } & $3^{\text {rd }}$ instar & 28.89 & 16.73 & 0.14 & -56.50 & 69.83 \\
& $1^{\text {st }}$ instar & -15.56 & 16.73 & 0.39 & -69.83 & 12.05 \\
\hline
\end{tabular}

natural enemies has become increasingly important for the success of biological control programs. The selection of biological control agents should be based on their potential for unintended impacts, self-replicating capacity, climatic compatibility, and their capability to maintain very close interactions with target populations [25]. Also, the biological controlling agent's adaptability to the introduced environment and overall interaction with indigenous organisms need to be considered prior to the introduction [26]. Until recently, the ecological role of environmental managers has been more concentrated on preventing damage from pollution rather than proposing sustainable solutions to different global and local problems faced by human societies. One of the multiple possibilities of applying ecological theories for human welfare is the use of our knowledge about the effects and mechanisms of predation, parasitism, and competition within various kinds of permanent and temporary aquatic habitats. By manipulating particular trophic levels, desired changes can be achieved in a system [27].

However, the application of Vorticella as a biocontrol agent should be further investigated because Vorticella sp. are ectocommensals that are prevalent in freshwater shrimps, attaching independently to their rostrum, gills, and appendages, acting as a parasite. Some species of Vorticella have also been reported among cultured tilapia in several farms in Saudi Arabia [28].

\section{Conclusions}

Present findings would be considered as a first step and basic information found for a new-avenue to work on mosquito larval controlling in an environmentally agreeable manner. $V$. microstoma studied in this work readily attach to Culex species mosquito larvae causing death in $C x$. tritaeniorhynchus (100\%) and Cx. gelidus (70\%) in 48 hours. However, this organism did not attach to Aedes species mosquito larvae and result in the death of Ae. albopictus and Ae. aegypti under the same experimental condition. V. microstoma used in this study acted as a good biocontrol agent against Culex larvae. Induced unfavorable conditions caused for the different morphological forms of $V$. microstoma and their encystation and excystation may appear as a better way for a time-lap under stressed changes in the environment.

\section{Data Availability}

The datasets supporting the conclusions of this article are included in the article. Data will not be shared in any of the sources.

\section{Conflicts of Interest}

The authors declare that they have no competing interests.

\section{Authors' Contributions}

HAKR conducted field surveys and data collection and wrote the manuscript; LDA designed the study, supervised the research, and wrote the manuscript. Both authors read and approved the final manuscript.

\section{Acknowledgments}

This work was supported by the University of Kelaniya of Sri Lanka under the research grant RP/03/02/07/01/2017. Funding provided by the University of Kelaniya of Sri Lanka under the research grant RP/03/02/07/01/2017 for data collection.

\section{References}

[1] B. Govindarajulu, A. Srimathi, R. Bhuvana, and J. Karthikeyan, "Mosquito larvicidal efficacy of the leaf extracts of Annona reticulata against Aedes aegypti," International Journal of Current Microbiology and Applied Sciences, vol. 4, pp. 132-140, 2015.

[2] J. J. Magadula, E. Innocent, and N. J. Otieno, "Mosquito larvicidal and cytotoxic activities of 3 Annona species and isolation of active principles," Journal of Medicinal Plant Research, vol. 3, no. 9, pp. 674-680, 2009.

[3] L. D. Amarasinghe and A. R. L. K. Rathnayake, "Prevalence of micro fauna associated with different mosquito breeding habitats in a selected area of Sri Lanka," International Journal of Current Microbiology and Applied Sciences, vol. 3, no. 5, pp. 587-598, 2014.

[4] H. E. Buhse and J. C. Clamp, "Vorticella," in Encyclopedia of Life Sciences, John Wiley \& Sons Ltd., Chichester, 2011.

[5] S. Viljoen and J. G. Van As, "Notes on the morphology and asexual reproductive processes of sessile peritrichs," Hydrobiologia, vol. 154, no. 1, pp. 75-86, 1987.

[6] H. Bick, Ciliated protozoa, World Health Organization, Geneva, 1972. 
[7] J. Muspratt, "Observation on the larvae of tree-hole breeding Culicini (Diptera: Culicidae) and two of their parasites," Journal of Entomological Society of South Africa, vol. 8, pp. 13-20, 1945.

[8] D. W. Micks, "The lethal effect of the ciliate, Vorticella microstoma Ehrenberg, on Anopheles quadrimaculatus," Journal of National Malaria Society, vol. 9, no. 3, pp. 256-258, 1950.

[9] D. W. Micks, "Vorticella infestation of Anopheles atroparvus Larvae," Journal of Economic Entomology, vol. 48, no. 2, pp. 215-216, 1955.

[10] H. Schober, "Observations on Culex pipiens larvae infected with Vorticella sp," Mosquito News, vol. 27, pp. 523-525, 1967.

[11] C. D. Patil, C. P. Narkhede, R. K. Suryawanshi, and S. V. Patil, "Vorticella sp: prospective mosquito biocontrol agent," Journal of Arthropod-Borne Diseases, vol. 10, no. 4, pp. 602-607, 2016.

[12] A. Warren, "A revision of the genus Vorticella (Ciliophora: Peritrichida)," Bulletin of the British Museum of Natural History (Zool), vol. 50, pp. 1-57, 1986.

[13] ALPHA, Standard methods for the examination of water and wastewater, American Public health Association, American water worker Association, Water Pollution Control Federation, New York, USA, 20th edition, 1998.

[14] F. P. Amerasinghe, "Illustrated keys to the genera of mosquitoes (Diptera: Culicidae) in Sri Lanka," Journal of National Science Council of Sri Lanka, vol. 23, no. 4, pp. 183-211, 2013.

[15] R. Rattanarithikul, B. A. Harrison, P. Panthusiri, and R. E. Coleman, "Illustrated keys to the mosquitoes of Thailand 1, Background; geographic distribution; list of genera, subgenera and species; and a key to the genera," The Southeast Asian Journal of Tropical Medicine and Public Health, vol. 36, no. 1, pp. 1-80, 2005.

[16] L. M. Rueda, "Pictorial keys for the identification of mosquitoes (Diptera: Culicidae) associated with dengue virus transmission," Zootaxa, vol. 589, no. 1, pp. 1-60, 2004.

[17] World Health Organization, "Guidelines for Laboratory and Field Testing of Mosquito Larvicides (2005),” 2019, http:// whqlibdoc.who.int/hq.

[18] J. O. Corliss, The Ciliated Protozoa: Characterization, Classification, and Guide to the Literature, Pergamon Press, London, 2nd edition, 1979.

[19] Q. Tahseen, I. M. Clark, and B. R. Kerry, "Vorticella sp. infestations in nematodes: a report," Nematologia Mediterranea, vol. 31, pp. 195-196, 2003.

[20] H. E. Finley and A. C. Lewis, "Observations on excystment and encystment of Vorticella microstoma," The Journal of Protozoology, vol. 7, no. 4, pp. 347-351, 1960.

[21] J. D. Stout, "Some observations on the ciliate fauna of an experimental meat digestion plant," Transactions of the Royal society of New Zealand, vol. 82, no. 1, pp. 199-211, 1953.

[22] A. F. Cabral, R. J. P. Dias, V. C. Oliveira, R. G. Alves, and M. D'Agosto, "Rhabdostylid ciliates (Ciliophora, Peritrichia, Epistylididae) as Epibionts on Chironomid larvae: evidence of high specificity and association with organic pollution," Zoological Science, vol. 35, no. 6, pp. 514-520, 2018.

[23] B. P. Das, "Chilodonella uncinata-a protozoa pathogenic to mosquito larvae," Current Science, vol. 85, no. 4, pp. 483489, 2003.

[24] A. H. Arthington and L. N. Lloyd, "Introduced poeciliidae in Australia and New Zealand," in Evolution and Ecology of Livebearing Fishes (Poeciliidae), G. K. Meffe and F. F. Snelson, Eds., pp. 333-348, Prentice-Hall, New York, 1989.
[25] J. K. Waage and D. J. Greathead, "Biological control: challenges and opportunities," Philosophical Transactions Royal Society of London, vol. 318, pp. 111-128, 1988.

[26] M. Denoth, L. Frid, and J. H. Myers, "Multiple agents in biological control: improving the odds," Biological Control, vol. 24, no. 1, pp. 20-30, 2002.

[27] X. He, M. D. Scheurell, P. A. Soranno, and R. A. Wright, "Recurrent response patterns of a zooplankton community to whole-lake fish manipulation," Freshwater Biology, vol. 32, no. 1, pp. 61-72, 1994.

[28] A. A. S. Abdel-Baki, M. M. Gewik, and S. Al-Quraishy, "First records of Ambiphrya and Vorticella spp. (Protozoa, Ciliophora) in cultured Nile tilapia (Oreochromis niloticus) in the central region of Saudi Arabia," Saudi Journal of Biological Sciences, vol. 21, no. 6, pp. 520-523, 2014. 